\section{Commentary: Down or non-Down: It all comes down to the details}

\author{
Matthew F. Mikulski, MD, ${ }^{\mathrm{a}}$ and \\ Carlos M. Mery, MD, MPH ${ }^{\mathrm{a}, \mathrm{b}}$
}

Many studies have found that patients with trisomy 21 (T21) tend to have better outcomes after atrioventricular septal defect (AVSD) repair than those without T21. ${ }^{1-3}$ This comes to no surprise to congenital heart surgeons, who in general find working with atrioventricular valves more challenging in patients without $\mathrm{T} 21$.

In this issue of the Journal, Ramgren and colleagues ${ }^{4}$ report on 62 nonsyndromic patients who underwent complex or noncomplex AVSD repair at their institution. The authors included mostly patients with complete AVSD, although 19 (28\%) patients had a restrictive ventricular septal defect, consistent with a transitional AVSD. The authors found that nonsyndromic patients without complex cardiac anatomy had short- and longterm outcomes comparable with those previously reported for patients with $\mathrm{T} 21$ but that mortality was significantly greater in those with complex anatomy. The authors concluded that anatomical factors were more important in predicting prognosis than the mere presence or absence of $\mathrm{T} 21$. The study specifically excluded patients with $\mathrm{T} 21$, thus making it impossible to have a direct comparison of outcomes.

The study demonstrates that good perioperative outcomes can be achieved in nonsyndromic patients. ${ }^{4}$ However, the incidence of reintervention is high. The

\footnotetext{
From the ${ }^{\mathrm{a}}$ Texas Center for Pediatric and Congenital Heart Disease, UT Health Austin/Dell Children's Medical Center; and 'Department of Surgery and Perioperative Care, Dell Medical School at The University of Texas at Austin, Austin, Tex.

Disclosures: The authors reported no conflicts of interest.

The Journal policy requires editors and reviewers to disclose conflicts of interest and to decline handling or reviewing manuscripts for which they may have a conflict of interest. The editors and reviewers of this article have no conflicts of interest.

Received for publication Aug 26, 2021; revisions received Aug 26, 2021; accepted for publication Aug 27, 2021; available ahead of print Sept 4, 2021.

Address for reprints: Carlos M. Mery, MD, MPH, Texas Center for Pediatric and Congenital Heart Disease, Dell Children's Medical Center, 4900 Mueller Blvd, Suite 3S.003, Austin, TX 78723 (E-mail: cmery@austin.utexas.edu).

J Thorac Cardiovasc Surg 2022;163:1446-7 0022-5223/\$36.00

Copyright $₫ 2021$ Published by Elsevier Inc. on behalf of The American Association for Thoracic Surgery

https://doi.org/10.1016/j.jtcvs.2021.08.062
}

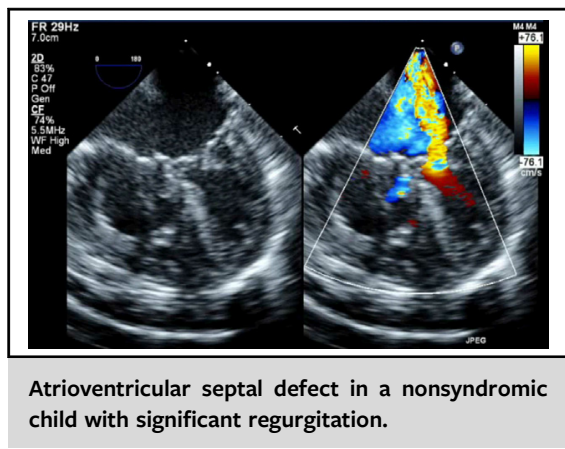

CENTRAL MESSAGE

Good perioperative outcomes can be achieved in nonsyn-

dromic patients with atrioven-

tricular septal defect, but

reintervention rates are high.

10-year incidence of reoperation in this cohort was almost $30 \%$, regardless of anatomy. This is greater than the $9 \%$ 10-year reoperation rate we reported after repair of noncomplex AVSD $(20 \%$ after complex AVSD) in a combined cohort where the majority of patients had T21. ${ }^{5}$ Some of these differences could potentially be explained by anatomic differences on the left atrioventricular valve that may make repair more challenging and reintervention more frequent (Figure 1). For example, in the current study with nonsyndromic patients, $20 \%$ to $25 \%$ of them (depending on complexity) had a deficient mural leaflet and 7\% to $13 \%$ had a single papillary muscle. ${ }^{4}$ In our study with combined T21 and non-T21 patients, only 5\% to $11 \%$ had a deficient mural leaflet and $2 \%$ to $4 \%$ a single papillary muscle. ${ }^{5}$

As suggested by Ramgren and colleagues, ${ }^{4}$ it is time to reframe the discussion surrounding AVSDs by placing more emphasis on the effect that anatomic complexity, rather than genetics alone, has on outcomes. Only by developing a good understanding of the anatomic nuances that impact outcomes in these patients will we be able to develop strategies to improve those outcomes. After all, it all comes down to the details.

\section{References}

1. Evans JM, Dharmar M, Meierhenry E, Marcin JP, Raff GW. Association between Down syndrome and in-hospital death among children undergoing surgery for 


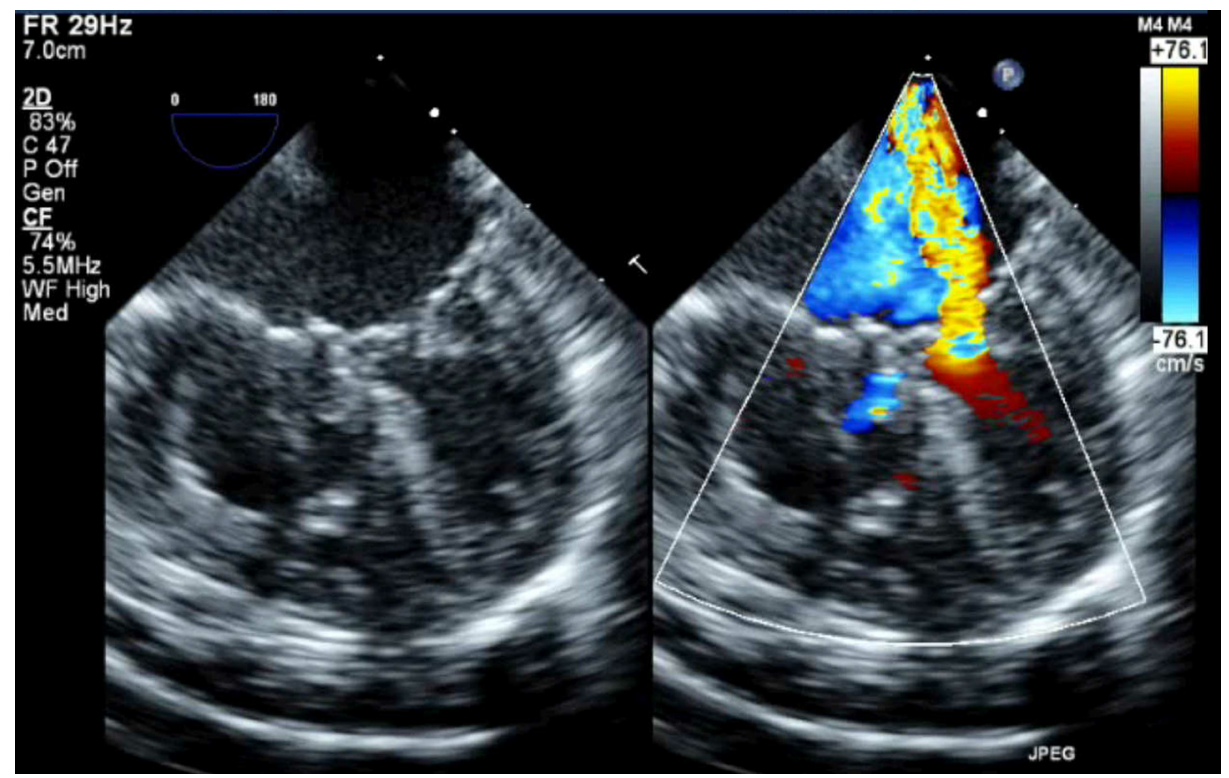

FIGURE 1. Four-chamber color-compare view of a transesophageal echocardiogram of a nonsyndromic infant with an atrioventricular septal defect demonstrating a dysplastic left atrioventricular valve with significant regurgitation.

congenital heart disease: a US population-based study. Circ Cardiovasc Qual Outcomes. 2014;7:445-52.

2. Formigari R, Di Donato RM, Gargiulo G, Di Carlo D, Feltri C, Picchio FM, et al. Better surgical prognosis for patients with complete atrioventricular septal defect and Down's syndrome. Ann Thorac Surg. 2014;78:666-72.

3. Dhillon GS, Ghanayem NS, Broda CR, Lalani SR, Mery CM, Shekerdemian LS, et al. An analysis of hospital mortality after cardiac operations in children with Down syndrome. Semin Thorac Cardiovasc Surg. 2020;32:947-57.
4. Ramgren JJ, Zindovic I, Nozohoor S, Gustafsson R, Hakacova N, Sjögren J. Impact of concomitant complex cardiac anatomy in nonsyndromic patients with complete atrioventricular septal defect. J Thorac Cardiovasc Surg. 2022;163: 1437-44.

5. Mery CM, Zea-Vera R, Chacon-Portillo MA, Zhu H, Kyle WB, Adachi I, et al. Contemporary outcomes after repair of isolated and complex complete atrioventricular septal defect. Ann Thorac Surg. 2018;106: 1429-37. 